\title{
MUITOS EM UM: O DUPLO NO CONTO "AS CORES DAS BOLINHAS DA MORTE”, DE IGNÁCIO DE LOYOLA BRANDÃO
}

\section{Antōnia Marly Moura da Silva* Francisco Edson Gonçalves Leite**}

Resumo: Ao longo da tradição, questões relacionadas à identidade suscitam reflexões em torno da noção de ser e de estar no mundo. Na modernidade, o tema ganha destaque na literatura, na qual o entrecruzamento de conceitos e metáforas da dualidade é representativo da condição de sujeitos cindidos. Sob tal perspectiva, este trabalho analisará o conto "As cores das bolinhas da morte", de Ignácio de Loyola Brandão (1936- ), em que o tema da dualidade configura-se numa atmosfera insólita vivenciada pelo protagonista. Na composição do drama das personagens, o esfacelamento do eu se emblematiza por meio da perda da sombra, metáfora indiciadora da procura pela real identidade e essência do sujeito, que assume o status de duplo da personagem.

Palavras-chave: Duplo. Fantástico. Conto contemporâneo.

\section{INTRODUÇÃO}

Q uestões relacionadas à identidade dos sujeitos, projetadas sob formas variadas, na criação artística e cultural de todos os tempos, sempre despertaram a curiosidade e o interesse do homem. Entretanto, foi a partir do Romantismo que as representações identitárias, principalmente no campo literário, apareceram com maior recorrência e proeminência. Por estarem intrinsecamente relacionadas à problemática da identidade, as representações do duplo na literatura seguem essa mesma tendência, pois se inserem nesse debate maior sobre a construção das identidades ao longo da história.

\footnotetext{
* Universidade Estadual do Rio Grande do Norte (UERN) - Mossoró - RN - Brasil. E-mail: marlymouras@uol.com.br

** Universidade Estadual do Rio Grande do Norte (UERN) - Mossoró - RN - Brasil. E-mail: edsongleite1@yahoo.com.br
} 
Nesse contexto atual em que as concepções de sujeito e de subjetividade são problematizadas, o mito do duplo demonstra sua fertilidade e seu poder de adaptação, configurando-se como um motivo literário por meio do qual são representadas as batalhas do eu pela busca da identidade. Essa recorrência ao mito do duplo na Modernidade, observada especialmente nas produções literárias das últimas décadas do século $\mathrm{XX}$, deve-se muito ao fato de que o sujeito moderno é cônscio de sua duplicidade. É, pois, nessa atmosfera de crise da subjetividade que se insere a narrativa de Ignácio de Loyola Brandão, "As cores das bolinhas da morte", integrante da obra $O$ homem que odiava a segunda-feira: as aventuras possiveis (2000). Nesse conto, buscar-se-á compreender as nuances e implicações do duplo, por meio da representação de um sujeito em crise.

\section{SOBRE O DUPLO}

Segundo Mello (2000), a duplicidade do eu é uma ideia antiga. De forma semelhante, Bravo (1998) vê o duplo como uma figura ancestral, ressaltando, por um lado, sua manifestação em culturas antigas e, por outro, sua permanência ao longo de uma tradição, ao manter sua vitalidade e poder nas produções artísticas, inclusive na Era Moderna. Além da disseminação temporal, o mito do duplo apresenta, também, um caráter universal, pois não se restringe a uma cultura específica, tampouco apenas a uma área determinada, inscrevendo-se, historicamente, em diferentes produções discursivas.

Ao longo da história, o fenômeno da duplicidade adquiriu diferentes nomenclaturas, embora todas elas, em última análise, mantenham a ideia central de desdobramento do eu, seja ele concebido objetivamente ou subjetivamente. López (2006) apresenta alguns dos termos correlatos à palavra "duplo", como: alter ego, sósia, "o outro", "segundo eu" e doppelgänger. Se os termos para denominar o fenômeno da duplicidade são múltiplos, também o são suas tentativas de conceituação e delimitação. Essa dificuldade advém, em parte, da própria ambivalência que está na base de sua constituição, bem como dos diferentes traços que adquiriu ao longo da tradição. Contudo, López (2006, p. 17) identifica um ponto central para o qual diferentes definições, em maior ou menor grau, convergem: "O proteico conceito de duplo gira em torno das noções de dualidade e binarismo, e se constrói em função de uma luta entre princípios, potências ou entidades opostas e complementares ao mesmo tempo".

Essa ideia de duplicidade, já presente em diferentes discursos ao longo da tradição, tem sua força renovada pelos estudos realizados por Freud (1996) e Jung (2008) nos campos da psicanálise e da psicologia analítica, respectivamente. Esses dois teóricos rompem com a concepção, até então vigente de uma unidade subjetiva do sujeito, e, ao conceberem-no como o resultado de uma dialética entre diferentes estruturas psíquicas, inscrevem a dualidade no interior do homem, como elemento constitutivo do ser.

Assim, o fenômeno da duplicidade transcende a visão mecanicista e unilateral à qual os olhos do homem moderno encontram-se acostumados. Isso justifica também a inquietação, principalmente no contexto da modernidade, que o duplo suscita, pois torna movediço o chão firme sobre o qual se ergue a arquitetura conceitual baseada na filosofia do esclarecimento. 
Na literatura, o tema do duplo encontrou campo fértil para sua propagação. Segundo Mello (2000, p. 11), essa recorrência ao motivo do duplo na produção artística de diversas épocas explica-se pelas questões inquietantes que essa temática sempre suscitou para a humanidade: “Quem sou eu?' e 'o que serei depois da morte?"'. Para Mucci (2006), o duplo encontra-se intrinsecamente ligado ao campo literário, reconhecendo, inclusive, que essa relação vai muito além da visão restrita que o concebe apenas como tema ou motivo para a criação artística.

Enquanto objeto de representação literária, o duplo manifesta-se como resultado de uma confrontação num mesmo espaço ficcional entre duas facetas de um mesmo personagem (o original e a cópia deste), com uma continuação física e/ou psicológica entre os dois (LÓPEZ, 2006). O encontro com o duplo apresenta-se sempre como inquietante e desestabilizador para o sujeito, visto que o desdobramento introduz questionamentos sobre sua identidade e unidade. Sua materialização no texto literário efetua-se por meio de elementos recorrentes, como o espelho, o reflexo, a sombra e o retrato, bem como de sequências narrativas que explicitam o conflito potencialmente presente nas manifestações da duplicidade: confrontação entre o original e seu duplo, usurpação de personalidade, dúvidas sobre a verdadeira identidade e impulso para aniquilar o rival.

A perda da sombra é, especificamente, um dos motivos literários que historicamente se prestou às representações do duplo. É sabido que a sombra é "[...] indissociável do, coexistente e simultânea ao objeto que ela duplica" (STOICHITA, 2011, p. 170). Essa proximidade levou muitas sociedades tradicionais a considerarem a sombra como manifestação e corporificação da alma e, portanto, o duplo do homem: "Uma série de investigações relacionadas ao folclore mostrou, sem dúvida alguma, que os homens primitivos consideram seu misterioso duplo, a sombra, como a real essência da alma" (RANK, 2014, p. 102). Esse misticismo atribuído à sombra transformou-a num poderoso símbolo, como reconhece Hendricks (2005). Em seu livro O corpo impossivel, Moraes (2002) reconhece duas variantes desse motivo literário, a saber: 1. a ênfase no encontro e na confrontação com o duplo; e 2. a perda da sombra pelas personagens. Em ambos os casos, há o questionamento da identidade dos sujeitos e, com isso, abre-se espaço para a representação do duplo, por meio de recorrentes atualizações e de reescrituras desse motivo nas narrativas contemporâneas.

As narrativas que tematizam o duplo, seja pelo motivo literário da perda da sombra seja por outros motivos, apresentam, em sua grande maioria, forte vinculação ao discurso fantástico. Isso porque a confrontação do sujeito com seu duplo é possibilitada pela construção de uma arquitetura narrativa que rompe com o discurso considerado lógico-racional, abrindo espaço para o insólito e para o incomum. Para Roas (2001), um dos teóricos contemporâneos influentes no debate sobre a natureza do fantástico, a essência do relato fantástico encontra-se na tensão estabelecida na trama narrativa entre o real e o irreal, o lógico e o ilógico, o racional e o irracional. Isso só é possivel porque o fantástico "[...] está inscrito permanentemente na realidade, a um só tempo apresentando-se como um atentado contra essa mesma realidade que o circunscreve." (ROAS, 2014, p. 52). Na narrativa de Brandão analisada a seguir, verifica-se essa estruturação do fantástico, em que o ilógico irrompe inesperadamente em situações corriqueiras das personagens e leva-as ao questionamento da própria noção de realidade. 


\section{SOB O SIGNO DA SOMBRA: “AS CORES DA BOLINHA DA MORTE”}

Ignácio de Loyola Lopes Brandão (1936- ) é romancista, contista, cronista e jornalista. Sua literatura apresenta, segundo Couto (2000), uma veia de inspiração kafkiana que metaforiza o absurdo da realidade ao retratar, recorrentemente, a solidão do ser humano em meio ao mundo contemporâneo. Contudo, o fantástico assume um aspecto peculiar na literatura de Brandão, pois, diferentemente de outros que constroem cenários místicos, a grande maioria dos contos desse escritor são ambientados no contexto urbano da cidade grande, tendo como personagem o indivíduo mediano, anônimo e sozinho, ainda que cercado pela multidão da metrópole. É nesse espaço de aparente normalidade que irrompe o evento insólito, estabelecendo, com isso, uma ruptura nas relações cotidianas.

Embora a fantasia seja o recurso usado pelo autor a fim de criar a atmosfera fantástica em seus contos (homens que perdem a mão ou a sombra, por exemplo), sua literatura não é alienada em relação ao contexto social circundante. Conforme afirma Silva (2001, p. 163), “A fantasia torna-se recurso para acolher melhor a realidade [...] com a diferença de que o elemento fantástico cumpre uma função de iluminar o contexto para a denúncia social, não para justificar o status quo". Esse comprometimento com a realidade pode ser evidenciado porque a transgressão do real funciona como ferramenta para deflagrar uma nova noção de real e, com isso, assume uma dimensão crítica que pode ser observada por dois aspectos principais. Em primeiro lugar, pela escolha dos próprios temas atuais, que questionam aspectos importantes sobre a realidade social moderna e, em segundo lugar, pela construção de suas personagens: seres normais à semelhança de qualquer ser humano, derrotados pelas próprias situações que enfrentam.

A maioria de seus textos aborda a penosa luta do homem não só pela sobrevivência física, mas, principalmente, pela estabilidade psíquica num cenário inóspito para a constituição egoica. Nesse contexto, visualiza-se a angústia do sujeito moderno, largado à própria sorte. O leitor acompanha, página a página, o drama de personagens irremediavelmente presos à engrenagem do capitalismo, uma rotina automatizada e burocratizada, que podam as possibilidades humanas de realização pessoal e o desenvolvimento da individualidade.

O conto de Brandão analisado a seguir, "As cores das bolinhas da morte", que integra a obra $O$ homem que odiava a segunda-feira: as aventuras possíveis (2000), coletânea na qual os eventos insólitos, ao aparecerem sob o rótulo de "aventuras possiveis", apontam para a banalização do absurdo na sociedade atual. Narrado em terceira pessoa, apresenta um enredo intrigante, no qual um acontecimento insólito irrompe inesperadamente no cotidiano e provoca uma reviravolta na vida do protagonista.

O conto tem como cenário o espaço urbano da grande cidade. A parte inicial da narrativa se passa na cidade de São Paulo e, a outra, na qual se dá o desfecho da história, na cidade de Belo Horizonte. Em ambos os cenários, o narrador faz descrições desses ambientes, caracterizando um espaço moderno em que o aglomerado de pessoas e a existência de prédios suntuosos juntamente com as favelas constituem simbolos distintivos da cidade grande. É nesse cenário que as ações das personagens são desenvolvidas. 
Nesse contexto, um juiz aposentado se vê ante uma situação incomum ao perceber que sua sombra sumira: "Olhando para o chão, não viu a sua sombra" (BRANDÃO, 2000, p. 95). Entretanto, a personagem reluta em aceitar essa perda; afinal, não estaria ela disfarçada num dia em que o sol se mostrava fraco? Apesar disso, o fato inexplicável se confirma e, ainda, em uma segunda-feira, dia que mais detestava.

O desaparecimento da sombra desestabiliza completamente a personagem. Tragada por essa atmosfera nebulosa, é convencida por um transeunte (que também perdera a sua), a procurar uma cientista chamada Cristina Agostino, em quem visualiza a possibilidade de obter uma explicação sobre o motivo da perda da sombra e, por conseguinte, recuperá-la. Nesse intuito, abandona sua rotina de juiz aposentado em São Paulo e desloca-se para a cidade de Belo Horizonte, onde residia tal pesquisadora:

Por que ele tinha entrado neste círculo? Até ontem vivia tranquilo, cumpria as obrigações rotineiras, não atrasava pagamentos, recebera até um diploma honoris causa da Receita Federal, por sempre ter declarado honestamente o imposto de renda. De um momento para outro estava rodando, em uma cidade desconhecida, sem lógica. Nada era racional e não sentia vontade de ir embora, poderia ficar a vida inteira aqui, se houvesse emprego. (BRANDÃO, 2000, p. 127).

Verifica-se, desse modo, uma ruptura total no cotidiano desse sujeito: ele abandona suas atividades diárias e, de forma mais impressionante e radical, o ambiente ao qual estava habituado, para se aventurar numa cidade desconhecida por ele. À primeira vista, parece uma atitude nada racional, mas é, contraditoriamente, motivada internamente pela razão: a crença de que o conhecimento científico, personificado na confiança nutrida pela cientista Cristina Agostino, dar-lhe-ia uma resposta convincente e aceitável. Na ação da personagem, a busca pelo conhecimento, um discurso hegemônico que determina os modelos de explicação e representação do mundo, ilustra, de modo exemplar, o papel desempenhado pelo discurso lógico-científico na sociedade moderna - afirmação que encontra sustentação no pensamento de Armstrong (2005) - para quem a sociedade ocidental moderna é filha do logos. No entanto, essa atmosfera racional é suplantada, na narrativa, pelo acontecimento fantástico, uma vez que esses questionamentos praticamente cessam na parte final da narrativa, e o protagonista se deixa envolver completamente pela atmosfera misteriosa do desaparecimento da sombra. No conto de Loyola, portanto, a realidade deixa de ser ponto de referência para a fabulação, ou seja, o contrato mimético torna-se desnecessário para dar vez ao confronto entre o racional e o irracional, uma das linhas de força estruturadoras do discurso fantástico.

Dada a natureza insólita das situações nas quais o protagonista se enreda, o leitor é levado a julgar grande parte das ações e atitudes dele como expressamente contrárias à racionalidade. O que pensar de um homem que chega para um atendente de uma universidade perguntando por uma professora que supostamente estaria a estudar o desaparecimento de sombras? A recomendação dada pelo funcionário é exemplar nesse sentido: “O senhor não quer consultar uma psicóloga?”' (BRANDÃO, 2000, p. 113). Assim, o julgamento que esse atendente faz da situação condiz perfeitamente com a interpretação realizada pelo leitor. 
Desse modo, é com o desaparecimento da sombra que esse embate se apresentará de forma mais complexa, visto que tal acontecimento, ao contrariar a razão, provoca uma reviravolta na vida do protagonista que, no entanto, aceita-a sem grande resistência. Embora durante boa parte da narrativa se deixe levar por essa atmosfera misteriosa, a racionalidade invade-o em alguns momentos, instaurando o conflito no interior de sua psicologia: " $\mathrm{E}$ a racionalidade o invadiu. Deu conta de que não fazia sentido estar em Belo Horizonte, uma cidade que não conhecia, dela só tinha ouvido falar [...]" (BRANDÃO, 2000, p. 138-139). Aqui, o discurso racional atua como espécie de superego, que o alerta sobre o perigo e a absurdez da situação insólita na qual se encontra. Além disso, ele se autodefine como um ser racional: "Era um homem racional [...]. O insólito não existe. Nem o absurdo. Quanto a isso, estava tranquilo.” (BRANDÃO, 2000, p. 104).

Essa confrontação, embora evidenciada com maior relevo a partir da perda da sombra, já se esboçava na mente do sujeito anteriormente a esse evento. Por meio de diálogos com outras personagens e do discurso do narrador, é dado a conhecer ao leitor que o homem sem sombra é um juiz aposentado. O fato do protagonista da história narrada ser um magistrado é particularmente interessante. No contexto ocidental, o judiciário é caracterizado por um discurso lógico-racional e impessoal, e tenta passar a imagem de uma rigidez comportamental condizente com as leis e normas que organizam a vida em sociedade. Na figura do protagonista, a quebra com esse discurso ocorre nas inúmeras transgressões da realidade, por exemplo, na ruptura de protocolos formais realizados pelo juiz, evento tido como anormal e da natureza da desordem e do absurdo, o que provoca indignação no tribunal: "Assombrou o tribunal ao propor ao réu a escolha da sentença: Jogar bolinhas de gude com mil delinquentes ou a morte" (BRANDÃO, 2000, p. 132). Como punição, o magistrado recebe a aposentadoria compulsória.

Como a primeira frase da narrativa já atesta a ocorrência do acontecimento insólito, a ênfase do enredo recai sobre a saga da procura empreendida pela personagem. Isso porque o sentimento de perda de uma parte de si mesmo vivenciado pelo homem sem sombra instaura em seu âmago uma série de questionamentos que, em última análise, refletem a psicologia de um sujeito em crise: "Se eu soubesse, ao menos, o que estou procurando; o que todos estão buscando." (BRANDÃO, 2000, p. 98). Desse modo, a busca da sombra empreendida relaciona-se inequivocamente à instabilidade das identidades representadas no contexto da sociedade moderna. Essa procura exterior pela sombra perdida tem como correlato interior um movimento psicológico realizado pela personagem na tentativa de encontrar a real essência de seu eu.

Sendo assim, a sombra é representada, no conto, como uma espécie de desdobramento ou duplicação do eu, como símbolo da existência humana. Isso justifica a relação de proximidade mantida com o "si" da personagem.

[...] As sombras são dependentes, fiéis, carentes, estimam a pessoa, se apegam. Sombras sofrem se, por alguma razão, se desligam dos corpos a que pertencem. Não sabem viver sozinhas, não sabem se adaptar a outros corpos. Vi um homem que tendo perdido a sombra, roubou uma. Só que o contorno da sombra era diferente do formado pelo corpo dele. Ficou muito estranho. Além disso, a sombra estava habituada a trajetos que o outro fazia e, às vezes o que roubou virava a esquina e a sombra continuava. (BRANDÃO, 2000, p. 106). 
Nessa passagem, é nítida a relação estabelecida entre a sombra e o sujeito. Ela é como uma parte duplicada do eu, e que, por essa razão, mantém uma relação de proximidade para com este; é a projeção de um eu, o seu complemento, a sua outra face; individualizada como esse eu, ela assume a forma e os contornos deste, não se adequando a outros indivíduos. Nesse sentido, verifica-se uma relação simbiótica entre homem e sombra, representada, na narrativa, para além do simples fenômeno físico.

Entretanto, não é somente o sentimento da perda que torna a sombra significativa para a personagem. A relação de proximidade estabelece-se anteriormente a esse evento incomum, conforme confessa o narrador da história: "Ninguém se dá conta se tem sombra ou não, a maioria pouco se importa. Parece não nos dizer respeito, está ali, podia não estar. Ele não. Costumava contemplá-la ao longo do dia, cheia de variações." (BRANDÃO, 2000, p. 96). Evidentemente, quando da percepção de sua ausência, a sombra adquire importância ainda maior. Parte natural, integrante de todo ser humano, sua falta transforma-se em característica diferenciadora desse sujeito: seria um "sintoma grave"? Alguma "doença"? A verdade é que o desaparecimento da sombra impactou-o profundamente, muito mais do que outros acontecimentos de sua vida, como a aposentadoria compulsória.

A partir dessas considerações, que significados podem ser atribuídos à simbologia da sombra no conto? Considerando o contexto moderno no qual a narrativa foi produzida, que sentidos a perda da sombra e sua busca podem adquirir? Para tentar elucidar essas duas questões, considerar-se-á a sombra sob três óticas, que, em todo caso, mantêm relações importantes com a arquitetura ficcional.

Numa retomada do texto bíblico, ver-se-á que a sombra precede a existência humana: "No princípio, Deus criou o céu e a terra. A terra estava sem forma e vazia; as trevas cobriam o abismo e um vento impetuoso soprava sobre as águas" (Gn 1.1-2). Nessa narrativa cosmogônica, as trevas estão associadas ao caos primitivo: a Terra encontrava-se vazia e amórfica. É a partir da palavra sacralizada de Deus, do Verbo, que esse caos originário transforma-se em cosmos. À luz, Deus chamou de dia, e, às trevas, de noite, inscrevendo a dualidade no âmago da criação cósmica. Há no conto, inclusive, uma referência a essa passagem bíblica, quando a personagem interroga se os homens teriam nascido da sombra: "Vai ver, os homens tenham nascido delas, porque quando o mundo ainda não existia, já havia a sombra, ela era tudo, era o universo. Até que surgiu a luz, surgiu o homem e elas decidiram que fariam parte desse mundo, de alguma forma" (BRANDÃO, 2000, p. 109).

Enquanto na Bíblia a sombra preexiste ao homem, no conto, a presença dela, segundo palavras do protagonista, parece confirmar a existência humana: "A sombra é a prova de que existimos" (BRANDÃO, 2000, p. 102). Em ambos os casos, a sombra relaciona-se, de algum modo, com a existência humana, precedendo-a ou confirmando-a. A partir disso, pode-se relacioná-la, portanto, ao primitivo, ao sombrio, ao desconhecido, às trevas, em oposição à luz.

Na psicologia, Jung (apud CAMPBELL, 2008, p. 99), ao teorizar sobre aspectos constituintes da psique e da personalidade humana, apresenta um conceito de sombra como oposto da consciência: "A sombra é, por assim dizer, o ponto cego da natureza individual. É aquilo que não se quer considerar sobre si mesmo" Desse modo, a sombra é aquilo que não é apreendido pela personalidade indivi- 
dual e é por ela excluído. Nesse sentido, sob o signo da sombra se aglomeram os elementos reprimidos pelo sujeito ao longo de sua formação enquanto ser social.

$\mathrm{Na}$ literatura, a sombra aparece como motivo literário e assume configurações próprias, muito embora sofra influência direta das duas outras dimensões do conceito apresentado anteriormente. Moraes (2002) reconhece, na literatura oitocentista, duas variantes desse motivo: na primeira, verifica-se uma ênfase no encontro e na confrontação com o duplo; na segunda, destaca-se a perda da sombra, tema tradicional de diversas lendas europeias, em que a sombra, embora se apresente, também, como uma extensão do eu, separa-se de seu dono, adquirindo independência.

Partindo dessas considerações, pode-se afirmar que a perda da sombra pelo protagonista do conto de Brandão e sua busca angustiante por ela representam, na verdade, a procura pela verdadeira essência do ser humano em um mundo cujas identidades se mostram instáveis, numa referência à constituição fragmentária do eu. Essa interpretação pode ser inferida pela combinação estabelecida entre diversas passagens da narrativa. De um lado, pode-se mencionar o bordão de um locutor de rádio que o protagonista, quando criança, costumava ouvir: "Ninguém sabe o mal que se esconde nos corações alheios. O sombra sabe" (BRANDÃO, 2000, p. 105). Estabelece-se claramente um jogo possibilitado pela dupla referência da palavra "sombra" que, de um lado, num plano simbólico, pode remeter à sombra concebida como um estrato da psique humana ao qual são relegados os impulsos e desejos incompativeis com a ordem socialmente estabelecida, denominados como "o mal que se esconde nos corações alheios". De outro lado, verifica-se, na narrativa, um jogo semântico criado pela correspondência entre o substantivo "sombra" e o adjetivo "sombrio": "[...] conheço a vida, já vi o outro lado do mundo, o aspecto sombrio do homem, sempre pronto a velhacarias" (BRANDÃO, 2000, p. 107); "Melhor que elas [as sombras] sumam, assim desaparece o lado sombrio da vida" (BRANDÃO, 2000, p. 148). Os trechos não tratam unicamente da sombra compreendida como fenômeno físico, portanto, impõe-se a necessidade de concebê-la também sob uma perspectiva mais ampla que considere e explore todo o simbolismo a ela inerente.

Ao representar também o lado sombrio da existência humana, pode-se estabelecer uma nítida correlação com a sombra em sua acepção psicológica, tal como postula Jung (2008). Em outra passagem da narrativa, lê-se: "A sombra é luz morta” (BRANDÃO, 2000, p. 102). A imagem criada pela caracterização da sombra como luz morta reflete, de modo inequívoco, a acepção desse conceito no campo psicanalítico. Evidentemente, a luz está para o conhecimento: "A luz sucede às trevas, tanto na ordem da manifestação cósmica como na da iluminação interior" (CHEVALIER; GHEERBRANT, 2009, p. 568). A expressão "luz morta", usada para definir a sombra, traz à tona o jogo de oposições e contradições que se encontram na origem desse conceito psicanalitico: um conjunto infindável de potencialidades inerentes ao sujeito humano, as quais, entretanto, permanecem adormecidas nas obscuras camadas do inconsciente. Por fim, a sombra é também considerada por outra personagem da narrativa como representativa da sensação de vazio humano: "Não tem importância. A sombra é o nosso vazio" (BRANDÃO, 2000, p. 148). Não seria essa sensação de vacuidade justificada pela existência de conteúdos psíquicos não assimilados pela consciência e que, portanto, permanecem desconhecidos pelo sujeito? 
No campo estritamente literário, o conto em análise filia-se à segunda variante do motivo literário da sombra, conforme postulado por Moraes (2002), pois nele a sombra não apenas se apresenta como uma extensão do eu, mas também adquire independência como resultado de uma cisão operada no sujeito. Desse modo, tal narrativa pode ser inserida no conjunto de uma tradição que estabelece diálogos com outras narrativas produzidas em diferentes épocas. Dentre essas narrativas, pode-se citar a narrativa de Chamisso, A maravilhosa história de Pedro Schlemihl (1814), que, segundo Moraes (2002, p. 101), precipita "[...] a criação de várias [narrativas] com enredos semelhantes". É o caso de Aventuras da noite de São Silvestre (1983), de Hoffmann, e A sombra (1983), de Andersen.

A recorrência de narrativas que tematizam a perda da sombra ressalta, pois, a importância da inscrição desse motivo literário em diferentes épocas, permitindo ao leitor analisar a narrativa como pertencente a uma tradição. Praticamente, todas essas narrativas inserem, inevitavelmente, o questionamento sobre a identidade no interior do sujeito. A cisão operada por meio da separação entre o corpo e a sombra é sempre sentida como a perda de uma parte importante e integrante do sujeito, resultando numa diferenciação negativa em relação aos demais membros do corpo social e, consequentemente, no enfraquecimento do sujeito. Entretanto, enquanto nas demais narrativas a perda da sombra parece estar atrelada a uma atitude consciente da personagem, no conto de Brandão tal evento insurge repentinamente, desestabilizando o protagonista da história e provocando uma reviravolta em seu cotidiano. Diferentemente das demais narrativas, nas quais a perda da sombra é percebida por todos, levando o sujeito portador dessa deformidade à completa exclusão das relações sociais, a personagem do conto de Brandão passa despercebida em meio à massa de desconhecidos habitantes das cidades grandes, o que ressalta a solidão vivenciada na modernidade: "Ficou parado, as pessoas passavam indiferentes, ninguém repara em nada” (BRANDÃO, 2000, p. 99).

Desse modo, percebe-se que a temática da perda da sombra leva, inevitavelmente, ao questionamento da real essência do sujeito, problematizando a construção da identidade no contexto da contemporaneidade. Freud (1996) já reconhecia que a civilização "[...] é em grande parte responsável por nossa desgraça e que seríamos muito mais felizes se a abandonássemos e retornássemos às condições primitivas". A sociedade, em prol de uma estabilidade, baseada num constructo social, dita o que é permitido ou não. Em virtude disso, muitos dos desejos e potencialidades do eu, por não condizerem com as normas de convívio social, acabam sendo reprimidos e excluídos, a fim de que não tragam ameaças à estabilidade do sujeito e da sociedade. Essa é a reflexão que faz a personagem em determinada passagem da narrativa:

A civilização não passa de fingimento, inibição. Os conceitos foram formulados para evitar que a humanidade se comporte como é, e deseja, e gostaria. Foram criados para nos tornar impotentes e angustiados. Por que nossas angústias [...] nascem da incapacidade que sentimos em não poder matar, roubar, violentar, mentir, cagar na rua, mijar na mesa em que se come, cuspir na igreja, tocar cuíca no tribunal, escrever provas em neozelandês nas universidades, praticar todo tipo de sexualidade, não ter religião, pudor, consideração, decência. (BRANDÃO, 2000, p. 157). 
Verifica-se, no fragmento destacado, um ataque e uma crítica ferrenhos às noções de civilização e moralidade que governam a vida em sociedade. Essa reflexão alinha-se, em certo sentido, ao pensamento do influente filósofo alemão Friedrich Nietzsche, no que se refere a sua postulação da transvaloração dos valores, que visa a libertar o homem dessas amarras morais historicamente construídas (cf. SANTOS, 2010). Contudo, embora reflita sobre essas ideias, a personagem encontra-se ainda distante do "homem do futuro" ou "além-do-homem", a quem Nietzsche delega tal atitude.

$\mathrm{Na}$ parte final da narrativa, especificamente quando o homem consegue entrar no prédio onde morava a escritora Cristina Agostinho - e não a cientista Cristina Agostino, que supostamente estudava sombras e parece não existir -, ele percebe que havia um resquício de sua sombra e se pergunta: "Estaria voltando? Se pudesse retê-la, ou quem sabe puxá-la, retirá-la dali, obrigá-la a se expor." (BRANDÃO, 2000, p. 145). Esse acontecimento pode ser entendido como indício do começo da descoberta da essência do eu, a qual se efetivará na parte final do conto. No desfecho, o protagonista se vê imerso em uma atmosfera obscura e inquietante: "Ele sabia e não queria ser aquilo em que tinha se transformado. Não podia admitir. De modo algum" (BRANDÃO, 2000, p. 163). Logo em seguida, o narrador afirma: "Ele, o juiz, homem sem sombra era o escuro" (BRANDÃO, 2000, p. 163). É nesse contexto que acontece a fusão entre homem e sombra, o que sinaliza a junção entre o eu e sua parte oposta: "E o juiz entendeu que, ao encontrar a sombra perdida, incorporara-se a ela. Tornara-se sua própria sombra" (BRANDÃO, 2000, p. 164). Nesse momento, além da fusão, há uma inversão hierárquica: o eu, a princípio superior, é absorvido e passa a ser subjugado pela sombra.

Dessa forma, o encontro da sombra perdida simboliza, antes de tudo, a descoberta da essência do sujeito. Nessa união, completa-se o processo de individualização, assim como o postula Jung (2008), na medida em que o sujeito assimila o outro como parte do eu, o que contribui para uma maior consciência da totalidade de sua personalidade. O percurso realizado pelo ser ficcional ao longo da narrativa pode ser compreendido como processo de aprendizagem e conhecimento de si, que tem seu ápice na consecução da individualização. Conforme destaca Cavalcanti (1997, p. 80), “Jung viu o confronto com a sombra [...] e o desnudamento da persona, como a condição básica inicial para o processo de individuação, para o encontro com o eu verdadeiro". No conto, o confronto da personagem com esse lado sombrio de sua personalidade é simbolizado pela perda da sombra e a consequente procura desencadeada. O sentimento de falta, resultado da cisão que separa o homem de sua sombra, leva-o a um profundo questionamento de sua existência, induzindo esse indivíduo a um maior conhecimento de si. Como decorrência desse processo, verifica-se também um paulatino desvestimento da persona, ou seja, da imagem ou máscara social sustentada pelo protagonista. Isso porque o juiz de direito, cuja função profissional é determinar, por meio de suas sentenças, o destino de outras pessoas, não é capaz, no âmbito de sua vida privada, de direcionar e controlar, mesmo que parcialmente, seu próprio destino, subjugado que se encontra pelos eventos incomuns que irrompem no seu cotidiano. Assim, o processo de individuação é caracterizado por um duplo movimento: de um lado, o confronto com a sombra; de outro, o desmascaramento da persona. 
Presume-se que a busca da sombra pelo protagonista é, na verdade, a procura pela essência do sujeito com todas as suas potencialidades. Considerando o ambiente burocrático no qual viveu imerso grande parte de sua vida, ditado por regras e normas rígidas de convivio, percebe-se, nessa procura angustiada realizada pelo protagonista, uma tentativa de libertação e de resgate de um eu reprimido por essas normas sociais. Esse conto permite, pois, uma reflexão sobre o sujeito imerso nessa sociedade moderna, em que os indivíduos cada vez mais se identificam com papéis sociais, relegando sua verdadeira essência para partes obscuras da psique. Há, no conto, uma perfeita caracterização do sujeito moderno, fragmentado e descentrado, cuja estabilidade e coerência não encontram mais espaço. Esvaziado de emoções e sentimentos, por um lado, e podado pelas rígidas normas de convivio social, por outro, eis a síntese do homem moderno, que a leitura do conto permite inferir. O conto delineia o retrato de um sujeito em crise, em constante atrito com o mundo no qual está imerso, cujas ações e atitudes não se revestem de nenhum heroísmo sobre-humano: o heroísmo é o do homem moderno em sua luta diária pela sobrevivência em uma sociedade cada vez mais inóspita.

Nesse conto, a sombra configura-se como o duplo da personagem. Essa interpretação advém não apenas do simbolismo que a sombra adquiriu para o homem ao longo dos tempos, mas, principalmente, pelo modo como o escritor problematiza a relação entre o ser ficcional e sua ausência de sombra. A proximidade e a intimidade entre o sujeito e sua sombra são reafirmadas inúmeras vezes ao longo do conto: ela é apresentada, inclusive, como o que estabelece uma relação única com o corpo que a projeta, ou seja, é individualizada, o que reforça a ideia de complementaridade entre essas duas partes. Se, no plano físico, a sombra é concebida como uma projeção, uma continuidade do sujeito; no plano simbólico - mais especificamente em sua acepção psicológica -, passa a figurar como um aglomerado de conteúdos psíquicos reprimidos, estabelecendo, portanto, a dualidade entre o consciente e o inconsciente. Essa interpretação ganha sustentação na narrativa pela frequente vinculação da sombra com o "lado sombrio" da existência humana.

Assim, a cisão que estabelece a separação entre o protagonista da narrativa e sua sombra acaba deixando profundas e graves consequências para o sujeito, uma vez que passa a ser portador de uma deformidade no plano físico que, inevitavelmente, reflete-se, principalmente, na psicologia desse sujeito, instaurando nele um conflito interior. O protagonista da narrativa de Brandão é emblemático quanto a isso, pois, ao verificar que sua sombra desaparecera, direciona toda a sua atenção e esforço para esse problema, na tentativa de encontrar uma solução. Entretanto, como observa Moraes (2002, p. 101), a cisão apresenta-se apenas como um primeiro estágio rumo à decomposição final: “[...] em várias narrativas a perda da sombra sugere uma antecipação da morte [...]". A parte final do conto não deixa claro o que realmente aconteceu com a personagem. Entretanto, a fusão do homem com sua sombra sinaliza para uma nova etapa na vida desse sujeito: "Estava iniciando uma viagem para o desconhecido absoluto" (BRANDÃO, 2000, p. 164). O novo ser que nasce dessa experiência pressupõe, ao menos no plano simbólico, a morte daquele indivíduo cindido anterior. 


\section{CONSIDERAÇÕES FINAIS}

A ficção fantástica de Ignácio de Loyola Brandão (1936- ) representa, de modo exemplar, a confluência, na trama narrativa, entre o insólito e o duplo, que passam a estabelecer uma relação simbiótica. Isso porque, ao contrário do que se verifica em algumas narrativas em que o fantástico serve apenas de pano de fundo para a representação do sujeito duplicado, a ficção de Brandão traz o fantástico para o primeiro plano da trama narrativa como forma de questionar a própria noção de realidade.

No conto analisado, o fenômeno da duplicidade opera-se por meio de uma cisão imposta à personagem. Essa cisão instaura um processo de busca pela parte faltante, o que, num plano metafórico, aponta para a procura da verdadeira identidade do sujeito em um mundo burocratizado e governado por rígidas normas de conduta e de comportamento que inibem a liberdade individual em prol de um suposto bem-estar coletivo. Para Chevalier e Gheerbrant (2009), a mutilação assume valor simbólico de iniciação. Na narrativa, essa iniciação é representada pelos questionamentos existenciais instaurados no interior do sujeito em razão da perda, o que o leva a uma melhor compreensão de si e do mundo a sua volta. Embora o intervalo entre a cisão e o desfecho da narrativa, que resulta na morte da personagem, seja curto, pode-se compreendê-lo como uma jornada rumo à individuação. A cisão exterior, verificada devido à perda da sombra, reflete, no plano subjetivo, um esfacelamento interior desse sujeito, expressão da instabilidade psíquica e de uma crise de identidade.

Dessa forma, pode-se concluir que a busca da sombra no conto "As cores das bolinhas da morte" remete à procura do duplo especular que permite ao sujeito diferenciar-se e reconhecer-se como uma individualidade. Nesse percurso, a sombra funciona como espécie de espelho, pois, ao configurar o outro da personagem, fornece a imagem especular que, no nível psicológico, permite a confrontação com o duplo e a construção de uma identidade autêntica. O reencontro e a fusão com a sombra representam um momento repleto de significados para o juiz, já que torna possivel a reintegração entre o eu e o outro. Essa fase demarca uma morte ao menos no plano simbólico, uma vez que o sujeito que emerge desse confronto diferencia-se do ser anterior cindido, que estava à procura de sua sombra.

Essa procura pela individualidade e pela diferenciação contrasta, pois, com os movimentos de massificação no processo de construção identitária e de dessubstancialização do sujeito humano verificadas no contexto atual, as quais acabam por igualar os sujeitos pela impossibilidade de expressão de suas potencialidades. Portanto, a perda da sombra nesse conto de Brandão desperta a personagem, que parecia viver no que Cavalcanti (1997, p. 214) define como escravidão psíquica: "A escravidão psíquica significa funcionar segundo a expectativa do outro, numa tentativa de adaptação, negando a verdadeira essência e excelência [...]".

Nota-se, ainda, que a manifestação do duplo nessa narrativa de Brandão está intimamente relacionada às infinitas possibilidades abertas pelo discurso fantástico. Em função disso, torna-se crivel para o leitor a história de um ser que, inesperadamente, visualiza a perda de sua própria sombra. É a própria concepção de realidade que é problematizada, uma vez que o acontecimento incomum irrompe dessa mesma realidade. Além de permitir o fenômeno da du- 
plicação, o fantástico abre também espaço, em Brandão, para a crítica a determinados aspectos da sociedade atual, como o processo de construção identitária no mundo moderno.

\title{
MANY INSIDE ONE: THE DOUBLE IN THE SHORTSTORY “AS CORES DAS BOLINHAS DA MORTE”, BY IGNÁCIO DE LOYOLA BRANDÃO
}

\begin{abstract}
Over tradition, questions related to identity raised reflections around the notion of being in the world. In modernity, the theme is highlighted in the literature, in which the interweaving of concepts and metaphors of duality is representative of the divided subject condition. From this perspective, this paper will examine the shortstory "As cores das bolinhas da morte" by Ignacio de Loyola Brandão, in which the theme of duality is portrayed in a strange atmosphere experienced by the protagonist. In the characters' drama composition, the disintegration of the self is represented through the shadow loss, a metaphor indicative of a seek by the subject for a real identity and essence, which assumes the status of the character's double.
\end{abstract}

Keywords: Double. Fantastic. Contemporary literature.

\section{REFERÊNCIAS}

ARMSTRONG, K. Breve história do mito. São Paulo: Companhia das Letras, 2005. BÍBLIA SAGRADA. Edição Pastoral. São Paulo: Paulus, 1990.

BRANDÃO, I. L. O homem que odiava a segunda-feira: as aventuras possiveis. 3. ed. São Paulo: Global, 2000.

BRAVO, N. F. Duplo. In: BRUNEL, P. Dicionário de mitos literários. Rio de Janeiro: José Olympio, 1998. p. 261-288.

CAMPBELL, J. Mito e transformação. São Paulo: Ágora, 2008.

CAVALCANTI, R. O mito de Narciso: o herói da consciência. 10. ed. São Paulo: Cultrix, 1997.

CHEVALIER, J.; GHEERBRANT, A. Dicionário de simbolos: mitos, sonhos, costumes, gestos, formas, figuras, cores, números. 24. ed. Rio de Janeiro: José Olympio, 2009.

COUTO, R. Kafka nos trópicos. EccoS Revista Científica, v. 2, n. 1, p. 105-107, jun. 2000.

FREUD, S. O mal estar na civilização. In: FREUD, S. Edição standart brasileira das obras completas de Sigmund Freud. Rio de Janeiro: Imago, 1996. 1 CD-ROM. JUNG, C. G. Individuação. In: JUNG, C. G. O eu e o inconsciente. 21. ed. Petrópolis: Vozes, 2008. p. 49-115.

HENDRICKS, W. J. The shadow as a metaphor for power. Minneapolis College of Art and Design, Minneapolis: 2005. Disponivel em: <http://www.artchangeslives.com/pdf/bHendricksThesis.pdf>. Acesso em: 23 fev. 2015. 
LÓPEZ, R. M. Las manifestaciones del doble en La narrativa breve española contemporanea. 2006. Tese (Doutorado em Literatura Espanhola)-Universidad Autónoma de Barcelona, Barcelona, 2006. Disponivel em: <http://www.tesisenred.net/TESIS_UAB/AVAILABLE/TDX-1013106-110206/rml1de1.pdf>. Acesso em: 11 ago. 2010.

MELLO, A. M. L. As faces do duplo na literatura. In: INDURSKY, F.; CAMPOS, M. C. (Orgs.). Discurso, memória e identidade. Porto Alegre: Sagra-Luzatto, 2000. p. 111-123.

MORAES, E. R. A vida dos simulacros. In: MORAES, E. R. O corpo impossivel. São Paulo: Iluminuras, 2002. p. 93-106.

MUCCI, L. I. O jogo especular do duplo. Recorte: revista de linguagem, cultura e discurso, n. 4, jan-jun. 2006. Disponivel em: <http://www.portais.unincor.br/ recorte/images/artigos/edicao4/4artigo_latuf.htm>. Acesso em: 11 ago. 2010.

RANK, O. O duplo: um estudo psicanalitico. Porto Alegre: Dublinenses, 2014.

ROAS, D. A ameaça do fantástico. In: ROAS, D. A ameaça do fantástico: aproximações teóricas. São Paulo: Editora UNESP, 2014.

SANTOS, V. L. F. dos. A crítica da moral e a transvaloração dos valores em Nietzsche: uma possibilidade para a formação de um indivíduo além-da-moral. 2010. Dissertação (Mestrado em Filosofia)-Universidade Federal de Pelotas, Pelotas, 2010. Disponivel em: <http://www.ufpel.edu.br/ich/ppgfil/dissertacoes / vani.pdf>. Acesso em: 15 ago. 2012.

SILVA, D. As mãos sujas: o longo fôlego das histórias curtas de um historiador solidário. In: QUINTANA, A. C. (Ed.). Cadernos de literatura brasileira: Ignácio de Loyola Brandão. São Paulo: Instituto Moreira Sales, 2001. p. 161-169.

STOICHITA, V. I. A short history of the shadow. Londres: Reaktion Books, 2011.

Recebido em 16-05-2016.

Aprovado em 22-09-2016. 